\title{
RISK TRANSFER OF PRESALE PROPERTIES AND \\ THE CONSTRUCTION OF A FORWARD PROPERTY \\ PRICE INDEX
}

\author{
BARBARA LEUNG and EDDIE HUI \\ Hong Kong Polytechnic University
}

and

\author{
BILL SEABROOKE \\ Cambridge University
}

\begin{abstract}
Despite the increasing use of forward contracts to pre-sell uncompleted properties, limited research has been conducted to explore the additional risks transferred from developers to buyers in presales of uncompleted properties. This research explored the risk-transfer mechanism specific to the forward property market and how the risks affect the construction of a forward property price index compared to that of spot property price indices. The proposed model using the repeat sales method for constructing the forward property price index is found to be more efficient over the other models in reflecting the general price change of the forward property market.
\end{abstract}

Keywords: Forward property market, presale property, risks

\section{INTRODUCTION}

For the past twenty years, developers in metropolitan cities like Hong Kong, London and Singapore are investing more in building bigger apartments, condominiums and large housing estates to meet the growing demand. Financing for these large-scale real estate projects is a major issue faced by developers. To release their financial burden, there has been an increasing use of forward contracts to sell off uncompleted properties at the planning or construction stage by developers, as opposed to spot properties which are sold upon their completion in the spot (completed) property market.

A forward presale property contract presents an agreement, such as the Agreement for Sale and Purchase (ASP) being used in Hong Kong, between a buyer/investor and seller/developer that the buyer commits to buying the property to be completed some time in the future at a pre-specified price, known as the forward price. The transfer of interest of the said property would be the date when the Occupation Permit (OP) of the building is issued. As such, investing in a presale property can generate no rental income to 
compensate for the cost of capital invested during the construction time-lag, i.e. the time between the presale ASP is signed and the OP of the property is released, which is also known as forward contract period. However, a down-payment ${ }^{1}$ has to be made by the buyer once the presale ASP is signed, and periodic installments are commonly required before the transfer of interest is exercised (Chau et al., 2003).

As shown in Table 1, the presales of uncompleted properties in Hong Kong accounts for a large proportion of the total number of property sales conducted in the first-hand market from 1993 to 2005 , ranging from $25 \%$ to as high as $78 \%$. Figure 1 shows the number of properties pre-sold compared to the property price index in the territory from 1993 to 2005. Although the number of presales transacted in the forward market was trending along the spot property price index in general, they are moving at a time lag. This implies that when property prices increased, particularly in 1997-98, more presales were offered by developers so as to capture the higher capital gain, vice versa, developers cut down their presales when the market was sluggish and handsome profits could not be realized; e.g. in the early 2000s after the Asian Economic Turmoil.

Table 1: Number of presales to total number of sales in first-hand property market

\begin{tabular}{|c|c|c|c|}
\hline Year & $\begin{array}{c}\text { Total no. of } \\
\text { sales }\end{array}$ & $\begin{array}{c}\text { Presales on uncompleted } \\
\text { properties }\end{array}$ & $\begin{array}{c}\text { \% of presales to total } \\
\text { sales }\end{array}$ \\
\hline 1993 & $23375^{*}$ & 18191 & $78 \%$ \\
1994 & $10778^{*}$ & 6525 & $60 \%$ \\
1995 & $4704^{*}$ & 3440 & $73 \%$ \\
1996 & 9109 & 4975 & $55 \%$ \\
1997 & 15500 & 12082 & $78 \%$ \\
1998 & 23384 & 17534 & $75 \%$ \\
1999 & 22121 & 11093 & $50 \%$ \\
2000 & 18151 & 5849 & $32 \%$ \\
2001 & 18539 & 8493 & $46 \%$ \\
2002 & 16541 & 9926 & $60 \%$ \\
2003 & 19047 & 7529 & $40 \%$ \\
2004 & 18566 & 4691 & $25 \%$ \\
2005 & 13495 & 8772 & $65 \%$ \\
\hline
\end{tabular}

Source: Data are extracted from the Economic and Property Research Centre (EPRC)

* Since the number of sales in the first-hand property market are not available, completed properties extracted from EPRC which are sold within the first year of completion are estimated as completed properties sold in the first-hand market

\footnotetext{
${ }^{1}$ It is a common practice in Hong Kong that a down-payment of $15 \%$ to $20 \%$ are required to be settled within 3 to 6 months after the signing of the Agreement for Sale and Purchase (ASP) of the presale properties so as to protect the developers against default on the purchase by the buyer (Apple Daily, 18 November 2005). However, if the market is sluggish, developers may lower the deposit required in between $10 \%$ to $15 \%$ (Next Magazine, 10 November 2005).
} 
Figure 1: Presale property transactions and the spot property price index: 1993-2005

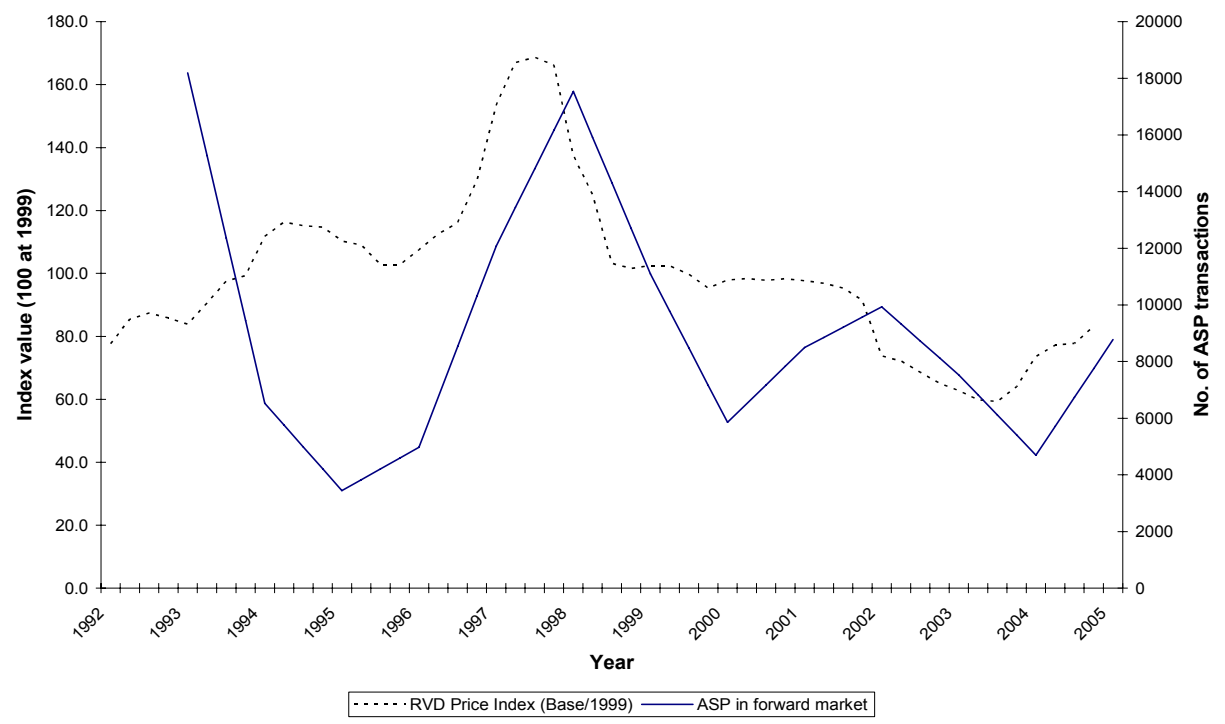

Source: Property price index published by the Rating and Valuation Department (RVD, 1995-2005)

The use of forward contracts to pre-sell uncompleted properties has gained increasing attention in the property markets of many countries because of the distinctive advantages it offers.

\section{From the perspective of developers}

From the perspective of developers, selective hedging can be attained through the use of forward markets to increase the efficiency of the price-forming process (Figlewski, 1981). The use of presales helps improve the cashflow of the development; it can also help developers hedge against any possible financial loss on the unsold properties when a price decline is expected by the time the construction is completed. As such, developers can mitigate their risks through the transfer of the equity interests of the uncompleted properties to the buyers. On the other hand, if the economic sentiment favors the property market, developers can use the earnings from the presales to reinvest in other construction projects to yield further returns.

\section{From the perspective of buyers}

On the contrary, anticipatory hedging is a more applicable explanation for purchases of presale properties from the perspective of buyers. The purpose of the hedge is to take advantage of the current price against any expected price appreciation of the property in the near future; in particular, when a boom market is anticipated (Carter, 1974). Furthermore, presale properties offer more choices to both home-seekers and investors to 
look for their desired dwellings/investments in terms of the location choice and the attributes available; in particular, when the spot market experiences a shortage of supply.

\section{Risk-transfer mechanism of a forward property contract}

Despite the benefits generated in the forward property market, buyers of presale properties have to bear the additional market risk and the cost of capital invested in the uncompleted properties transferred from the developers during the construction time-lag as shown in Figure 2. Unlike financial contracts, no dividend in the form of rental income will be paid to the buyers on the uncompleted properties bought during the construction time-lag and so the buyers have to bear the cost of capital invested in the uncompleted properties during the forward contract period (Chau et al., 2003). For example, most of property purchases in Hong Kong are financed through the arrangement of a mortgage and the mortgage rates fluctuate in accordance to the demand and supply of funds in the market. The higher the mortgage rate and the longer the construction time-lag, the higher the capital finance risk that presale property buyers have to bear.

In regard to the market risk, the price movement of presale properties during the construction time-lag should, in principle, track along that of the spot property market if they possess the same market risks. However, there is a suggestion that presale property buyers are willing to pay a premium for hedging against the anticipated price appreciation; in particular, when the market is in a boom and a shortage of supply of spot properties is experienced as discussed under the benefit section. Therefore, there may be times that prices in the forward property market deviate from that of the spot market because of the higher premium paid.

\section{Figure 2: Risk-transfer mechanism of a forward property contract}

Forward risks transferred from developers to presale property buyers during the construction time-lag

- Market risk

- Capital finance risk

Extensive research has been conducted to develop comprehensive models for studying the price behavior of spot property markets (Locke 1990; Tse 1997; Draper \& Findlay 1982; Bailey et al. 1963; Rosen 1974; Chau et al. 2005). However, investigations on the nature of the additional risks embedded in a forward property contract as discussed above and how these risks being reflected in the forward property price index are limited. Among the very few studies, Chau et al. (2003) conducted an empirical study which set up a price discovery function for the construction of a forward property contract price index. In this respect, following the exploration of the benefits and risks arising from the risk-transfer mechanism embedded in a presale property, this research will review the models available for the construction of both forward and spot indices, with a view to proposing an appropriate model for the development of a forward property price index for examining 
the price behavior with respect to the additional forward risks embedded (Figure 2). As Hong Kong is a pioneer in using forward contracts to pre-sell large-scale housing developments, there are sufficient amount of sales data available for the study.

\section{LITERATURE REVIEW}

Extensive research has been conducted to establish comprehensive models for constructing property price indices. Locke (1990) adopted the adjusted present value technique in pricing a property investment which is considered free from arbitrary judgment. Tse (1997) introduced the use of a mixed autoregressive and moving average model known as ARIMA model to study the pattern of real estate prices; in particular, to show how to determine the cyclical turning points in a real estate price series. Draper and Findlay (1982) made a comparative study on the use of Capital Asset Pricing Model (CAPM), Arbitrage Pricing Theory (APT), and Hedonic Price Model (HPM) on estimating the price appreciation on real estate based on the market equilibrium concept.

Chau et al. (2005) examined the various methods for construction of property price indices being used in Hong Kong and summarized the three main difficulties encountered using transaction-based methods. Firstly, property markets are usually thin with properties not transacted often. Secondly, the measured price change is contaminated by the variation of quality due to the heterogeneous characteristics of different properties contained in the periodical data set. Thirdly, the quality of a property may change over time due to aging. For these reasons, a price index constructed using transaction-based methods may undesirably capture the change in the quality of a property over time apart from the general price change (Bailey et al., 1963). Some researchers advocated the use of a valuation-based method to circumvent the insufficiency of transaction-based methods. However, problems such as the types of variables to be included in the pricing model and the appraisal-smoothing effect have yet to be addressed (Geltner et al., 2003).

Another method which has been broadly disseminated is the use of the repeat sales method based on Rosen (1974). Rosen (1974) formulated the hedonic pricing model (HPM) to show that properties can be described by packages of a number of attributes, such as location, size and facilities. Each property has a quoted market price which reflects the implicit value of the attributes embedded in that property, and this implicit value guides both buyers and sellers' choices regarding the packages of attributes bought and sold. By incorporating a set of coefficients of time dummies into the HPM, a series of price indices can be computed in the model as shown in Equation 1 (Palmquist 1980; Shiller 1993; Quigley 1995),

$$
\ln S_{t}=\sum_{j=1}^{J} \beta_{j t} X_{j t}+\sum_{t=1}^{T} \alpha_{t} D_{t}+\varepsilon_{t}
$$

where: 
$\ln S_{t}=\operatorname{logarithm}$ of the transaction price of the spot property at time $t$

$\beta_{j}=$ implicit price for the $j^{\text {th }}$ property characteristic $X_{j}$

$X_{j}=$ housing attributes from $j=1$ to $J$ which formed the property characteristic

$\alpha_{t}=$ logarithm of the price index at time $t$

$D_{t}=$ time dummies set to 1 if the property was sold at time $t$ and set to 0 if otherwise

$\varepsilon_{t}=$ error term with mean zero and variance $\sigma_{\varepsilon}^{2}$

The Repeat Sales Pricing Model (RSPM) developed by Shiller (1993) is built along the theoretical framework of HPM. It states that the quality of a spot property possesses a package of attributes which remain unchanged between times. Under this assumption, all spot properties have the same price path through time and changes in the price index occur only in response to changes in prices of individual property sold to indicate the time value required on the capital invested to cover the market risks borne between the two sales. Adapting the theoretical framework, Chau et al. $(2003,2005)$ formulated the functional form using repeat sales method as shown in Equation 2 for the construction of spot price index,

$$
\begin{gathered}
\ln S_{t_{2}}-\ln S_{t_{1}}=\sum_{j=1}^{J} \beta_{j}\left(X_{j t}-X_{j t}\right)+\sum_{t=1}^{T} \alpha_{t}\left(D_{t_{2}}-D_{t_{1}}\right)+\left(\varepsilon_{t_{2}}-\varepsilon_{t_{1}}\right) \\
\ln S_{t_{2}}-\ln S_{t_{1}}=\sum_{t=1}^{T} \alpha_{t} D_{t}+v_{t}
\end{gathered}
$$

where:

$t_{1}$ and $t_{2}=$ time of the first sale and second sale of the property

$D_{t}=$ time dummies measuring the change of price index between the holding period of the property, the dummy is set to 1 if the property was sold at time $t_{2},-1$ if the property was sold at time $t_{1}$, and to 0 if otherwise

$\alpha_{t}=$ logarithm of the price index in the spot property market

$v_{t}=$ error term.

This method has the advantage of avoiding the functional form required in the HPM of measuring the unique characteristics of the properties; however, the model has been criticized for its ignorance of the aging effect. As Yiu (2002) stated that as a building ages, its productivity declines due to physical deterioration of the building structure. 
Chau et al. (2003) also extended the use of repeat sales method to construct a Forward Contract Repeat Sales (FCRS) model for pricing forward properties ${ }^{2}$ and for investigating the equilibrium relationship between the spot and forward property markets. To construct the FCRS model, Equation 3 is rewritten as,

$$
\ln F_{t_{2}}-\ln F_{t_{1}}=\sum_{t=1}^{T} \gamma_{t}\left(D_{t_{2}}-D_{t_{1}}\right)+\eta\left(y_{t_{2}}-y_{t_{1}}\right)+e_{t}
$$

where:

$\ln F_{t_{2}}, \ln F_{t_{1}}=$ logarithm of the forward prices of the forward property at $t_{2}$ and $t_{1}$

$\gamma_{t}=$ logarithm of the price changes in the forward property market

$y_{t_{2}}-y_{t_{1}}=$ discount required to compensate the rental loss during the construction timelag

$\eta=$ coefficient attached to the discount factor

$e_{t}=$ error term

To apply Equation 4 for constructing a forward property price index, pair sales of uncompleted properties with both transacted only in the forward market are employed for the study. Equation 4 implies that any difference between the forward pair prices depicts (i.e. in form of forward-forward (F-F) pair sales) not only the change of price indices between the two sales, it should also reflect the discount required to cover the dividend, in the form of rental income, lost during the forward contract period. Chau et al. (2003) also pointed out that since the forward sales employed for testing the model are all uncompleted properties which are free from physical depreciation, the FCRS property price index constructed are, therefore, free from the multicollinearity problem between the building age and time.

Figure 3 shows the FCRS Index constructed using forward pair sales based on Equation 4 and the spot property price index, i.e. the HKURS Index, using spot pair sales based on Equation 3 published by the Hong Kong University. Although the result shows that the trend of the FCRS Index reconciles in general with the HKURS Index, there are two questions arisen. Firstly, it shows that the FCRS Index overshot the HKURS Index in many periods. It may be due to the reason that the repeat sales model used for contructing the HKURS Index (Equation 3) fails to take asset depreciation into account, causing the spot prices to be underestimated over time.

${ }^{2}$ They are uncompleted properties traded in the forward market which include both presale properties offered by developers and those with subsequent re-sales while they are still under construction. 
Secondly, it is apparent that the FCRS Index fluctuated more vigorously between the time-periods comparing to the HKURS Index. The reason is very likely attributed to the limited data available for the periodical testing. Only 3,062 forward pairs are available compared to 270,000 spot pairs for the test which covers a study period of 120-months from 1991 to 2000. Therefore, it is not surprising that the limited data collected for the FCRS Index in each month might be susceptible to bias on certain property types ${ }^{3}$. For example, there was a big drop on the forward prices of approximately $16 \%$ during the month of June in 1997, and then a big rise of approximately $14 \%$ followed in the next month; whereas, in reality, the property market was as a whole enjoying a steady surge during the year 1997 until the outbreak of Asian Financial Turmoil in October.

\section{Figure 3: FCRS property price index and HKURS spot-pair sales property price index}

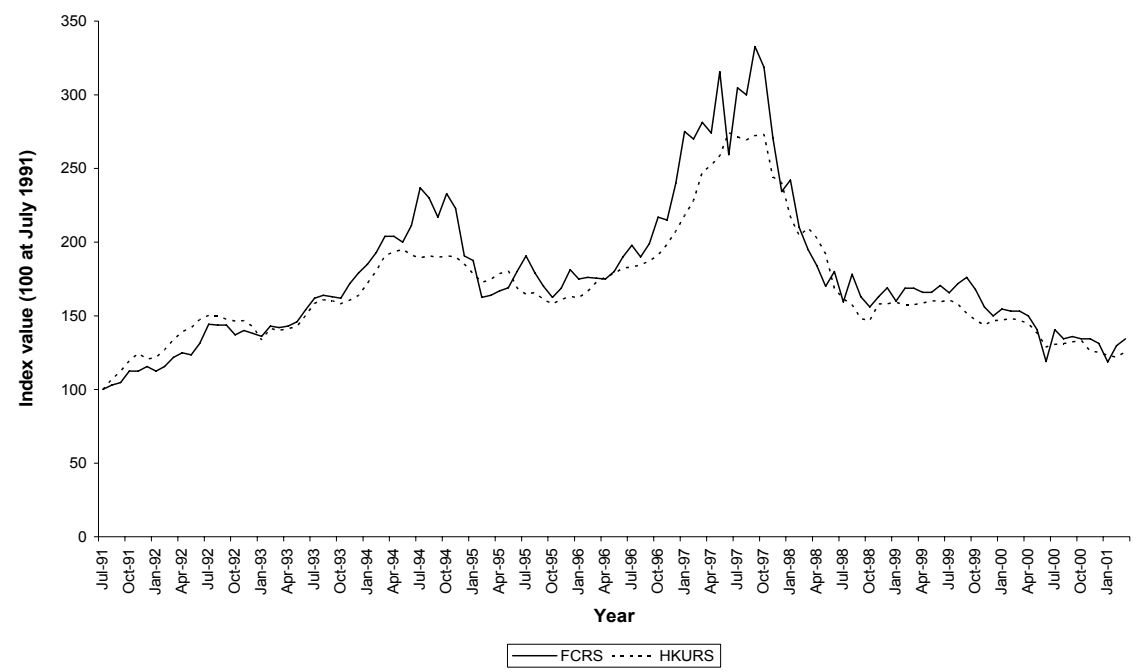

Source: Chau et al. (2003)

${ }^{3}$ The residential stocks included in the study are defined as independent self-contained domestic units followed the definition adopted by the Rating and Valuation Department. They are categorized into 5 Classes according to their size measured in saleable area. Class A properties are considered as small units of less than $40 \mathrm{~m}^{2}$. Class $B$ and $C$ are medium units which are most popular in the territory. Class $D$ and $E$ properties are considered as large units from $40 \mathrm{~m}^{2}$ to $99.9 \mathrm{~m}^{2}$. 


\section{METHODOLOGY}

Chau et al. (2003) made a first attempt in building the FCRS model for construction of the first forward property price index using forward properties which has induced important insights for further research in this area, despite the limitations discussed above. To enhance the validity of the results generated from the FCRS model, a promising means is to increase the size of the data set. Relying purely on uncompleted properties contained in the repeat pair sales certainly limits the data available. If the data set can be expanded, whilst all the first transactions remain as forward sales, to allow the second sales to include spot transactions of the same set of properties in the forward property repeat sales (FPRS) pairs, i.e. in form of forward-spot (F-S) pair sales, the data set can be enlarged to improve the validity of the index constructed. Also, the difference of the FCRS F-F pair sales can reflect only a portion of the discount required for compensating the rental loss during the construction time-lag since the project remains unfinished when the second forward sale is conducted. But the difference of the FPRS F-S pair sales is able to capture the full compensation required covering all the forward risks of the forward property by comparing its price sold in the forward market with its price sold in the spot market in its subsequent sale. Apart from the speculators who wish to earn a quick return through buyand-sell in the forward property market, many forward property buyers are actually investors and/or home-seekers who intend to keep their properties for a longer period ${ }^{4}$. For these buyers, a forward property price index constructed using F-S pair sales of the same set of properties can reflect more effectively the amount of risk involved in investing in a forward property compared to a spot property.

\section{The FPRS model}

With the use of forward-spot pair sales, the FPRS model is developed in Equation 5 for measuring the general price change of forward properties written as,

$$
\begin{aligned}
& \ln S_{t_{2}}-\ln F_{t_{1}}=\sum_{t=1}^{T} \alpha_{t} D_{t}+\phi(r \tau)+\gamma A_{t_{2}}+\varepsilon_{t_{1} t_{2}} \\
& \ln \frac{S_{t_{2}}}{F_{t_{1}}}=\sum_{t=1}^{T} \alpha_{t} D_{t}+\phi(r \tau)+\gamma A_{t_{2}}+\varepsilon_{t_{1} t_{2}}
\end{aligned}
$$

where:

\footnotetext{
${ }^{4}$ From the twelve housing estates randomly selected in the sample set, 5583 properties are found to have forward pair sales conducted during the study period. Among them, both the first two sales of these properties transacted in the forward market (while they were still under construction when the two sales were transacted) accounts for only 7\% (369 pairs), whereas the first sale was transacted in the forward market and the second sale transacted in the spot market accounts for 93\% (5214 pairs).
} 
$D_{t}=$ time dummies measuring the change of price index between the holding period of the property, the dummy is set to 1 if the properties was sold at time $t_{2}$ in the spot market, -1 if the property was sold at time $t_{1}$ in forward market, to 0 if otherwise

$\alpha_{t}=$ coefficients attached to the time dummies, $D_{t}$

$r=$ net compounded discount rates required in the market

$\tau=$ construction time-lag

$r \tau=$ total discount required to compensate for the rental loss during $\tau$

$\phi=$ coefficient attached to the discount factor, $r \tau$

$A_{t_{2}}=$ age of the property at the second spot sale at $t_{2}$

$\gamma=$ coefficient attached to the aging factor, $A$

$\varepsilon_{t_{1} t_{2}}=$ error term contained in the price difference during the period $t_{1}$ to $t_{2}$

Equation 6 implies that the differences between the F-S pair prices depicts not only the change of prices reflecting in the index between the two sales, $D_{t}$, it also reflects the discount required to cover the additional capital finance risk, $r \tau$, during the construction time-lag as illustrated in Figure 1. Based on risk-return equilibrium, the forward property price movements indicated by $D_{t}$ should be able to reflect the level of risk of the respective properties borne in the forward market. If the forward properties during the forward contract period possess the same level of market risk borne by spot properties, the returns required from the repeat sales of forward properties and that of spot properties should then be similar and, as such, their price indices should track along closely with each other. Any deviation between the two price indices, forward and spot, would suggest otherwise.

The cost of capital transferred, $r \tau$, fluctuates with the movement of mortgage rates in accordance with the supply and demand of funds in the market. Since no rental income will be generated during the construction time-lag to cover the cost of capital borne by forward property buyers, the higher the mortgage rates, the higher the capital finance risk transferred, and the higher the discount required by the buyers from the forward prices to cover the cost of capital. Furthermore, since a spot property forms the pair sales and aging effect, $A$, would thus be taken place in the equation.

A log-linear function is used as the form of the regression so that it is able to measure the percentage change of the property returns for a unit change of the time variables incorporated in the model. The time variables include both the time dummies for 
measuring the price index and the aging factor for measuring the depreciation rate of the properties (Gujarati 2003).

Note that the problem of multi-collinearity between the time dummies and the aging factor does not exist in this FPRS model. The time dummies represent the change of the price index during the holding period, i.e. from the forward sale conducted at $t_{1}$ until the spot sale at $t_{2}$; whereas the age takes place only when the property is completed (which should be some time after the forward sale at $t_{1}$ ) until the second sale is conducted at $t_{2}$. Therefore, the time dummies would not track exact synchronization, with the proxy measuring the age of the property. Based on the FPRS model shown in Equation 6, three different forward property price indices are constructed using different specifications for comparison purposes:

Model 1: Index using full FPRS model taking both the discount factor and aging factor

$$
\ln \frac{S_{t_{2}}}{F_{t_{1}}}=\sum_{t=1}^{T} \alpha_{t} D_{t}+\eta(r \tau)+\gamma A_{t_{2}}+\varepsilon_{t_{1} t_{2}}
$$

Model 2: Index taking consideration of the discount factor

$$
\ln \frac{S_{t_{2}}}{F_{t_{1}}}=\sum_{t=1}^{T} \alpha_{t} D_{t}+\eta(r \tau)+\varepsilon_{t_{1} t_{2}}
$$

Model 3: Index without consideration of the discount factor and aging factor

$$
\ln \frac{S_{t_{2}}}{F_{t_{1}}}=\sum_{t=1}^{T} \alpha_{t} D_{t}+\varepsilon_{t_{1} t_{2}}
$$

\section{Data sources}

Quarterly property prices from the years 1993 to 2005 are extracted from various sources for constructing the different price indices.

Forward-Spot Repeat Sale (FPRS) Price Indices - A total of 5583 properties are found to have forward pair sales from twelve randomly selected housing estates, and the data of the repeat sales are extracted from EPRC for constructing the forward property price indices. In order to reflect accurately the amount of risks involved in investing in a forward property vis-a-vis a spot property, only properties which have forward-spot (F-S) pair sales transacted during the study period are selected for the validation. That is, the first sale was transacted in the form of presale offered by the developer when the property was still under construction, and the second sale was transacted in the spot market some time after the completion of the property (F1-S). There are altogether 5415 properties found to have F1-S pair sales for forming the sample set. The rest of 168 properties which have only forward-forward (F-F) pair sales transacted in the forward market are excluded from 
the test in order to avoid contamination of the exacerbated speculative effect imposed in the construction of the indices. Also, the age of the 5415 properties contained in the sample set are no more than 10 years old so that a better control on the change of quality of the properties can be exercised; and the first 5 percent of the upper range and lower range sale transactions have been excluded from the sample set to avoid a biased effect created by the outlying extreme prices.

Indices from other sources are also used for comparing with the FPRS Index which include:

All Forward Property (FC) Price Index - All uncompleted properties sold in the forward market (Table 1) from 1993 to 2005 are extracted from EPRC. A purely transactionbased forward property price index (without adjustment) is constructed by taking the quarterly average prices of all these forward sales.

RVD Spot Property Price Index - It is the longest price index published by the Rating and Valuation Department (RVD) of the Hong Kong Government. The index adopts a transaction-based method using the property prices of virtually all transacted properties in the territory. The market average prices are then adjusted by the rateable value of the subject properties in order to measure the price changes with quality of the properties being kept at a constant. Because of its wide coverage and long history, the RVD Index forms the primary source of price indices that practitioners make reference to in Hong Kong (RVD, 1995-2005).

RVDSP Spot Property Price Index - It is another price index published by RVD for the Selected Popular Residential Developments (SPRD). The housing estates included in the SPRD are all large self-contained estates which share similar characteristics in terms of periods of construction, building style, facilities and properties attributes offered and its popularity in the districts. Apart from the RVD Index, RVDRS is also a popular index that practitioners make reference to because of its distinctive characteristics (RVD, 19952005).

Repeat Sale Spot Property Price Index - Spot property price index using the repeat sales method developed by Chau et al. (2005) based on the model developed in Equation 3, i.e. the HKURS Index, is also constructed for comparison purposes. The data are extracted from the database of the Department of Real Estate and Construction, The University of Hong Kong (HKU, 2005).

Regarding the discount rate used to measure the additional cost of capital during the forward contract period, the mortgage rate is considered to be an appropriate proxy. It is the practice of the developers in Hong Kong that when they determine a discount on presale properties, they will consider to what extent the discount will be accepted by the prospective buyers for covering the mortgage cost in keeping the uncompleted property during the construction time-lag. As such, the combined impact of the mortgage rate 
together with the construction time-lag is considered an appropriate proxy to measure the discount required for setting the presale prices of the uncompleted properties. The mortgage rates generally fluctuate with the best lending rates, and the best lending rates can be extracted from the database of the Hong Kong Monetary Authority (HKMA) .

Table 2: Descriptive statistics of the FPRS forward property indices 1993-2005

\begin{tabular}{lllll}
\hline & Minimum & Maximum & Mean & $\begin{array}{c}\text { Standard } \\
\text { Deviation }\end{array}$ \\
\hline F1 properties, $F_{t_{1}}\left(\mathrm{HK} \$ / \mathrm{ft}^{2}\right)$ & 1700 & 11000 & 4600 & 1362 \\
\hline S properties, $S_{t_{2}}\left(\mathrm{HK} \$ \mathrm{ft}^{2}\right)$ & 1002 & 12762 & 4485 & 1768 \\
\hline $\begin{array}{l}\text { Discount rate, } r \text { (yield per } \\
\text { annum) }\end{array}$ & 0.050 & 0.103 & 0.076 & 0.017 \\
\hline $\begin{array}{l}\text { Construction time-lag, } \tau \\
\text { (year) }\end{array}$ & 0.003 & 1.762 & 0.595 & 0.294 \\
\hline $\begin{array}{l}\text { Total compounded discount } \\
\text { (total yield) required, } r \tau\end{array}$ & 0.0003 & 0.161 & 0.054 & 0.028 \\
\hline $\begin{array}{l}\text { Age of spot properties, } A \\
\text { (year) }\end{array}$ & 0 & 10 & 2.8 & 2.5 \\
\hline No. of F1-S pair sales & 5415 & & & \\
\hline
\end{tabular}

Table 3: OLS results of the FPRS forward property price indices

\begin{tabular}{lccc}
\hline Variable & $\begin{array}{c}\text { M1 (Full FPRS Model) } \\
(\mathrm{t} \text {-stat) }\end{array}$ & M2 (t-stat) & M3 \\
\hline $\begin{array}{l}\text { Discount factor } \\
(\phi)\end{array}$ & $1.6821(7.44)$ & $\begin{array}{c}1.8734 \\
(23.48)\end{array}$ & -- \\
\hline Aging factor $(\gamma)$ & $-0.0195(-0.90)$ & -- & -- \\
\hline Adj R $^{2}$ & 0.88 & 0.88 & 0.87 \\
\hline
\end{tabular}

\section{EXAMINATION OF THE FPRS FORWARD PROPERTY PRICE INDICES}

As expected, the discount factors contained in $\mathrm{M} 1$ and $\mathrm{M} 2, r \tau$, show a positive coefficient $\phi$ of 1.6821 and 1.8734 which evidenced that a discount from the price difference is embedded between the F1-S pair sales in order to compensate for the

The best lending rates can be extracted from the website of HKMA, www.info.gov.hk/hkma/index.htm. 
additional cost of financing the capital during the construction time-lag as suggested in Figure 2. Whereas in M1, the aging factor shows a negative coefficient of -0.0195 which is approximated at an instantaneous rate of $1.9 \%$ per annum ${ }^{6}$ in depreciation of the properties' values.

\section{Figure 4: Comparison of the forward property price indices}

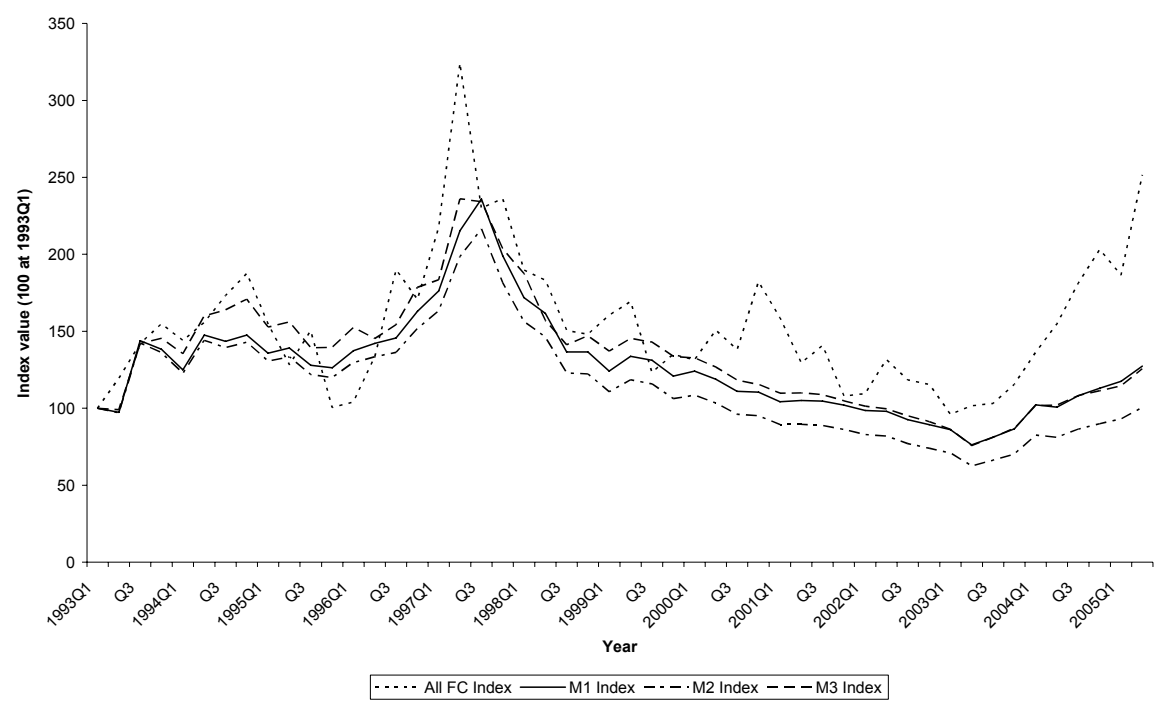

Figure 4 contains the following four different forward property price indices scaled to a base of 100 at the $1^{\text {st }}$ quarter of 1993 :

All FC Index is constructed by use of the average prices of all forward properties M1 Index is constructed by use of FPRS taking discount factor and aging effect M2 Index is constructed by use of FPRS taking discount factor only M3 Index is constructed by use of FPRS without taking discount factor or aging effect

The figure shows that all the different forward property price indices are trending in similar pattern in general. However, the All FC Index constructed by use of purely transaction-based forward properties fluctuated more vigorously than that of FPRS Indices (M1, M2 and M3 Indices). It is due to the reason that uncompleted property forward sales are, very often, concentrated on a few housing estates in a particular time-period and thus the prices are more likely to be biased towards certain types of properties. The problem is similar to that of FCRS Index shown in Figure 3. Although the FCRS Index is constructed using the repeat sales method, the data collected in each monthly period are

${ }^{6}$ For estimation of the depreciation rate, refer to Gujarati (2003), pp. 179-180. 
limited to purely uncompleted properties of the F-F pair sales. It renders the problem that the forward prices available in each monthly period are likely to be biased on certain types of properties.

The other three indices, M1, M2 and M3 using different specifications, are tracking along closely with each other. Among them, the M3 index lies well above the M1 and M2 indices during most of the study period because it takes no consideration of the discount factor in the index construction, whereas the discount factor has been embedded in the construction of M1and M2 for compensating the rental lost during the construction timelag. The three indices are constructed based on the price differences of the F1-S pair sales

of the same properties and are scaled at the same base of 100 at the $1^{\text {st }}$ quarter of 1993. If the price differences for constructing the index are not adjusted by the different discounts imposed during the study period, the index constructed using the unadjusted price differences will be distorted in reflecting the general price change of the forward property market. It is because the level of the unadjusted price change reflected in the index in some time-periods will be higher than the return required for covering the market risk borne if the discounts of those time-periods are higher than that of the origin. The deviation implies that the larger the discount required during the time-period, the larger the gap between M3 and M1/M2 because of the higher additional cost incurred. The discount factor, $r \tau$, during the study period averaged at $5.4 \%$.

Regarding the M2 index which takes the discount factor into consideration but not the aging factor, it tracks along very closely with the M1 index in the early years but then consistently falls behind in later years. Since the aging effect of the forward properties does not take place when the forward sales are conducted in early years, but when depreciation of the properties takes place in later years, a lower value is reflected in the price index of M2. Therefore, it would not be surprising that the M2 index displays a downward movement compared to the M1 index in which aging factor has been considered in keeping the quality of the properties constant. The M1 FPRS index which takes both the discount factor and aging factor can reflect more accurately the general price trend of the forward property market.

\section{COMPARISON OF THE FPRS (M1) INDEX WITH THE SPOT PROPERTY PRICE INDICES}

This section examines whether the forward property market works as efficiently as that of the spot property market in reflecting the market sentiment by comparing the various price indices of the two markets. Figure 5 compares the FPRS (M1) with the following different spot property price indices commonly used in Hong Kong which include:

RVD All Classes Index built by using all spot properties adjusted by rateable values RVDSP Index covers the Selected Popular Residential Developments in Hong Kong HKURS Index built based on Equation 3 using all pair sales of spot properties 
The figure shows that the FPRS index trends along closely with the other spot property indices; in particular, with the RVDSP index as the properties contained in both data sets share similar characteristics - they are all popular self-contained housing estates with similar facilities and housing attributes. This finding agrees with the proposition of Chau et al. (2003) that forward properties are priced as efficient as the spot properties in reflecting the market sentiment so as the market risks. Meanwhile, it is interesting to note that the HKURS index, similar to the M2 index shown in Figure 4, falls behind the FPRS index and other indices in times due to the reason that the former index has taken no consideration of the aging factor for the construction of the index.

\section{Figure 5: Comparison of FPRS (M1) Index with the spot property price indices}

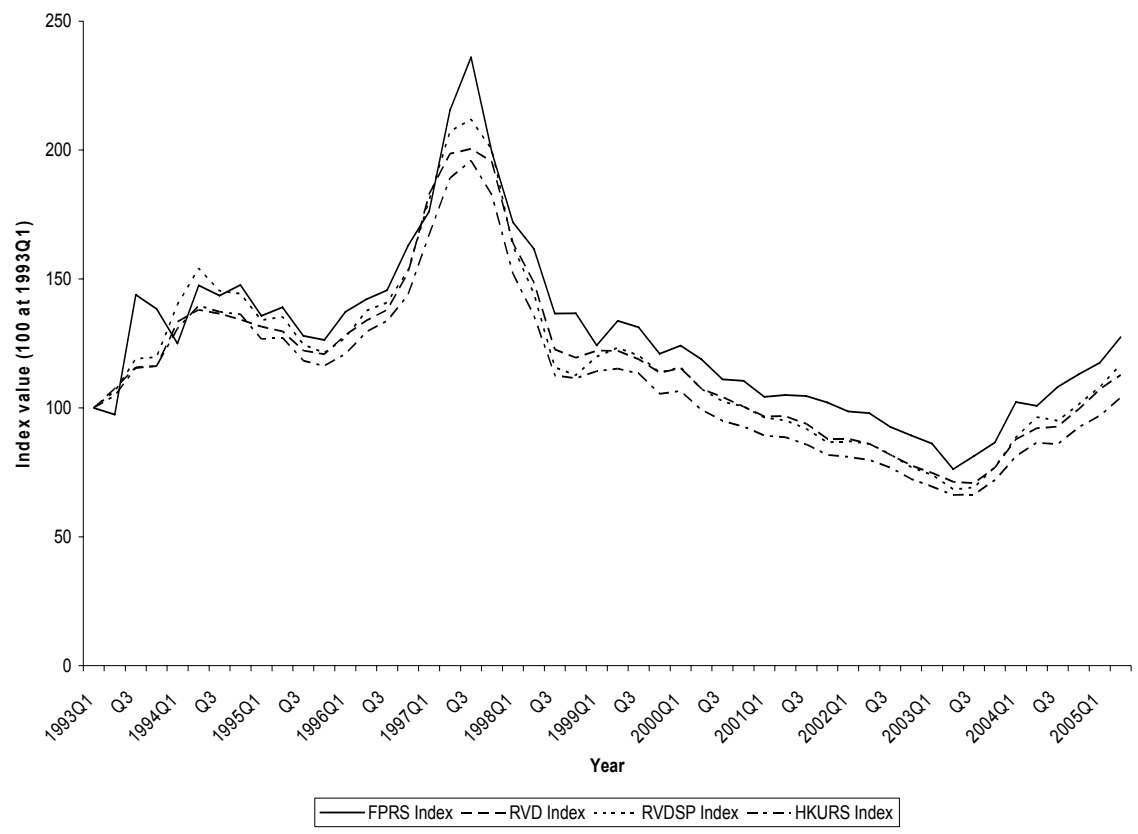

Source: RVD 1995-2005; HKU 2005

Despite the trend of the FPRS index reconciling in general with the spot price indices, the FPRS index drifted slightly above the spot indices in some years. The price movements of the spot indices have fallen a little behind that of the FPRS index; in particular, in the years 1997, mid-1999 and early 2004, at an average rate of around $6 \%$ to as high as $9 \%$ in 1997. This is in line with the proposition that buyers are willing to pay a premium on forward properties to hedge against any anticipated price appreciation in times when the market is in a boom or shows sign of revitalizing. This also agrees with the observation from the market that a premium has been imposed on the pricing of properties sold in the 
first-hand market in which forward sales are active because of the anticipated higher price (Next Magazine, 2004 and 2005; Lee, 2005).

\section{CONCLUSION}

There has been an increasing use of forward contracts to pre-sell uncompleted properties, This study is conducted to explore the additional risks embedded in a presale of an uncompleted property and how the risks are reflected in the construction of the forward property price index in Hong Kong. It has made an attempt to outline the risk-transfer mechanism on how developers are able to pass part of their project risks, including the forward market risk and the additional capital finance risk incurred during the construction time-lag, onto the buyers through the use of forward property contracts. An improved repeat sales method using forward-spot pair sales (FPRS), which is able to reflect the specific forward risks embedded, is developed for construction of the forward property price index.

The results show that a discount factor for compensating the loss of rent during the construction time-lag is embedded in the formation of the forward property prices. This discount factor must be taken into account in the construction of forward property price indices; otherwise, the price changes reflected in the forward index to indicate the general price change of the forward properties with respect to their market risks borne will be distorted. The discount factor is correlated to the mortgage rate and the length of the construction time-lag, the higher mortgage rate and the longer construction time-lag, the higher discounts are imposed in the forward property prices.

Comparison of the FPRS index with the spot property price indices used in the market shows that the pricing of presale properties in the forward market reconciles that of the spot properties in general in reflecting the overall market risks. Yet, the spot price indices were found falling slightly behind the FPRS index in some years when the market was in a boom or showed sign of revitalizing, at an average rate of $6 \%$ to as high as $9 \%$. It seems to agree with the proposition that buyers were willing to pay a premium on forward properties in order to hedge against any anticipated price appreciation in the near future; in particular, when the spot market was in a boom and experiencing a shortage of supply.

The FPRS index is considered being capable of reflecting the market risks specific to the forward property market for use by both practitioners and investors in their investment appraisals. It can, on one hand, keep the quality of the properties measured constant by using repeat sales method and, on the other hand, mitigates the weakness of the previous FCRS model that limited forward sales could cause serious data bias as a result of likely clustering of certain types of properties in a particular time-period. Also, by using forward-spot pair sales, the FPRS model can reflect more accurately the amount of risk involved in investing in a presale property vis-a-vis a spot property. 


\section{Acknowledgements}

The authors would like to acknowledge the funding given by the Research Centre for Construction and Real Estate Economics of the Department of Building and Real Estate, the Hong Kong Polytechnic University, for the collection of the large quantity of data.

\section{REFERENCES}

Apple Daily (2005), "Property News”, Apple Daily, 18 November, p. J1.

Bailey, M.J.; Richard, F.M.; Muth, R.F. and Nourse, H.O. (1963), “A regression method for real estate price index construction", American Statistical Association Journal, December .

Carter, R.L. and Doherty, N.A. (1974), Handbook of Risk Management, Kluwer-Harrap Handbooks, London.

Chau, K.W., Wong, S.K. and Yiu, C.Y. (2003), "Price discovery function of forward contracts in the real estate market: An empirical test", Journal of Financial Management of Property and Construction, 8(3), pp. 129-137.

Chau, K.W.; Wong, S.K. and Yiu, C.Y. (2005), "Real estate price indices in Hong Kong", Journal of Real Estate Literature, 13(3), pp. 337-356.

Draper, D.W. and Findlay, M.C. (1982), "Capital asset pricing and real estate valuation", AREUEA Journal, Summer.

Esha, Z. (2003), "Build then sell, is it practical to implement it in Malaysia?" Conference Proceedings, The CIB Student Chapters International Symposium 2003, Department of Building and Real Estate, The Hong Kong Polytechnic University.

Figlewski, S. (1981), "GNMA passthrough securities: Futures trading and volatility in the GNMA market", The Journal of Finance, XXXVI(2), May.

Geltner, D.; MacGregor, B.D. and Schwann, G.M. (2003), "Appraisal smoothing and price discovery in real estate markets", Urban Studies, 40(5/6), pp. 1047-64.

HKSAR (1997), Report on Sales Descriptions of Overseas Uncompleted Residential Porperties, The Law Reform Commission of Hong Kong.

HKSAR (2002), Local Completed Residential Properties: Sales Descriptions and Precontractual Matters, Summary Report, The Law Reform Commission of Hong Kong.

HKU (2005), Repeat Sales Index, http://hkusury2.hku.hk/hkdata. 
Ko, K. (2005), "Set your target”, Property Guide, South China Morning Post, Autumn, pp. $8-9$.

Lee, A. (2005), "Purpose power: Go through our checklist before you sign on the dotted line, Property: An essential guide for homebuyers and tenants", South China Morning Post, Autumn, p. 15.

Lee, C.M. (2005), “The government which works for the property developers", Next Magazine, 26 May, pp. 152.

Locke, S.M. (1990), "Property investment analysis using adjusted present values", Appraisal Journal, 58(3), pp. 373-380.

Next Magazine (2003), "Gold-Face Holdings failed to completed Villa Pinada”, 29 May.

Next Magazine (2004), "Presale properties in China", 2 December 2004 and 10 November 2005.

Palmquist, R.B. (1980), "Alternative techniques for developing real estate price indexes", Review of Economics and Statistics, 62(3), pp. 442-448.

Quigley, J.M. (1995), “A simple hybrid model for estimating real estate price indices”, Journal of Housing Economics, 4(1), pp. 1-12.

Rosen, S. (1974), "Hedonic prices and implicit markets: product differentiation in pure competition", Journal of Political Economy, 82, pp. 34-55.

RVD (1995-2005), Hong Kong Property Review, 1993 to 2005, Rating and Valuation Department, HKSAR, Hong Kong.

Shiller, R.J. (1993), "Measuring asset values for cash settlement in derivative markets: Hedonic repeated measures indices and perpetual futures", Journal of Finance, XLVIII(3), July.

Tse, R.Y.C. (1997), "An application of the ARIMA model to real estate prices in Hong Kong”, Journal of Property Finance, 8(2), pp. 152-163.

Yang, Z. (2001), “An application of the hedonic price model with uncertain attribute: The case of the People's Republic of China", Property Management, 19(1), pp. 50-63.

Yiu, C.Y. (2002), The effects of age on housing prices in Hong Kong, Unpublished PhD thesis, The University of Hong Kong. 